\title{
Seasonal variability of anthropogenic indices of PAHs in sediment from the Kuala Selangor River, west coast Peninsular Malaysia
}

\begin{abstract}
Rapid increase in industrialization and urbanization in the west coast of Peninsular Malaysia has led to the intense release of petroleum and products of petroleum into the environment. Surface sediment samples were collected from the Selangor River in the west coast of Peninsular Malaysia during four climatic seasons and analyzed for PAHs and biomarkers (hopanes). Sediments were soxhlet extracted and further purified and fractionated through first and second step column chromatography. A gas chromatography-mass spectrometry (GCMS) was used for analysis of PAHs and hopanes fractions. The average concentrations of total PAHs ranged from 219.7 to $672.3 \mathrm{ng} \mathrm{g}-1 \mathrm{dw}$. The highest concentrations of PAHs were detected at $964.7 \mathrm{ng} \mathrm{g}-1 \mathrm{dw}$ in station S5 in the mouth of the Selangor River during the wet inter-monsoonal season. Both pyrogenic and petrogenic PAHs were detected in the sediments with a predominance of the former. The composition of hopanes was homogeneous showing that petroleum hydrocarbons share an identical source in the study area. Diagnostic ratios of hopanes indicated that some of the sediment samples carry the crankcase oil signature.
\end{abstract}

Keyword: Olycyclic aromatic hydrocarbons; Biomarkers; Riverine sediment; Pollution sources; Malaysia; Oil 